Int. J. Speleol. 20 (1991): 23-35

\title{
Population size of Pyrenean troglobiont coleopters (Speonomus species) in a cave in Belgium
}

\author{
Raymond Tercafs *,** and Christine Brouwir*
}

\begin{abstract}
SUMMARY
The population size of three troglobitic species of Speonomus (Coleoptera Bathysciinae) from the Pyrenees, intentionally introduced in 1969-1970 into the "Grotte de Ramioul" cave (Province of Liège, Belgium) has been studied using the mark-recapture technique. It has been shown that the three cave levels possess large Speonomus populations (upper network: 12,718; middle network: 13,902; lower network: 18,249 individuals) and that the superficial underground environment is also colonized, including the schist area. The most abundant species is Speonomus longicornis (relative frequency between 0.73 to 0.89 ). The two other species are present in the relative frequency between 0.04 and 0.23 for $S$. diecki, and between 0.03 and 0.11 for $S$. stygius.

The overall Speonomus population size in the cave is estimated at 44,000 individuals.
\end{abstract}

\section{INTRODUCTION}

Three speciès of troglobiont Bathysciinae Coleopters have been intentionally introduced into the Ramioul cave (Borough of Flémalle, province of Liège, Belgium) by Bouillon and Hubart (1982). They are Speonomus diecki Saulcy, Speonomus stygius Dieck, from the Surroque mountain mass (Saint-Girons, Ariège, France) and Speonomus longicornis Saulcy from the Plantaurel mountain mass (Foix, Ariège). On June 3, 1969, 200 Speonomus longicornis were released at a depth of 60 metres below the plateau. On May 8, 1970, 100 Speonomus stygius and 80 Speonomus diecki were also released at a depth of 30 metres. These proportions between species released were

$$
\text { Belgium }
$$

* Institute of Zoology, Liège University, quai Van Beneden, 22, B-4020 Liège, Research 
chosen by experimenters in so far as, according to knowledge at the time, they corresponded to the proportions generally encountered in the stations of origin. These 380 specimens introduced into the cave seem to have found conditions there favourable for their development and expansion. Trapping carried out some years later revealed hundreds of individuals (Hubart, 1983). It was therefore of interest to study in greater detail the expansion of these transplanted species, evaluating the present population densities in the different levels of the cave and measuring the relative proportions of the three species. It was also useful to verify the expansion of the Speonomus towards the superficial subterranean medium near the cave.

\section{MATERIAL AND METHODS}

\section{Description of the study site}

The Ramioul cave is situated at Ivoz-Ramet (coordinates Lambert: $224.97 / 141.24)$. It is entirely comprised in the carboniferous limestone which it crosses throughout its width. It is travelled through by an underground stream which enters the soil by sinkholes at the southern end of the limestone. Coal-bearing schists covered with humus are contiguous to the limestone mass and extend northwards (Hubart, 1983; Quinif, 1985). The cave is composed of three levels:

- an upper level, fossile rich in speleothems;

- a middle level, also fossile, poor in concretions;

- a lower level, accessible from the middle level by a 30-metre well. It is an active network about 700 metres long.

The temperature of the cave is fairly stable at around 7 to $9.5^{\circ} \mathrm{C}$. Maximum variations are observed in the lower part of the cave, where the underground stream has thermal influence. In winter the air temperature is $7 \pm 0.5^{\circ} \mathrm{C}$; in June it is $8.2 \pm 0.4^{\circ} \mathrm{C}$. During the experimental period ( 15.04 .87 - 26.06.87), the following air temperature were recorded: lower network: $8.2-8.6^{\circ} \mathrm{C}$; middle network: $8.4-9.0^{\circ} \mathrm{C}$.; upper network: $8.4-9.2^{\circ} \mathrm{C}$. The relative humidity, even in the dry period, never decreases below 98\%. Trophic resources are unequally distributed (Delhez et al., 1973): - the upper level is poor in alimentary resources apart from roots and woody wastes;

- the middle level encloses a series of hibernating and estival 
trogloxene species subsisting in latency for several months;

- the lower level receives a large quantity of organic materials during the water rise.

\section{Marking individuals}

Speonomus longicornis have been captured and marked on the elytrons with a spot of model-making paint, using a fine paint-brush. To test the resistance of the mark to humidity and chafing, the animals were placed in a terrarium the bottom of which is lined with damp plaster covered with clay. The terrarium was kept at $5 \pm 1{ }^{\circ} \mathrm{C}$, in a dark cold room. Food consists of pieces of cheese. After four months it was found that the individuals still bear a coloured mark. Of the 20 specimens at the beginning of the experiment, four were dead. A second marking was then made on the remaining sixteen individuals. After two months, both marks were still visible and no mortality was observed. Examination by a scanner electron microscope showed that the paint was well localized on the surface of the elytrons, where it was held firm by the thorns covering them. The mark did not spread and did not penetrate under the elytrons. There was no paint on the tergite's cuticles. This technique and the type of paint used therefore seemed suitable for the purpose of the study, since they enable effective long sterm marking. It is analogous to the technique used by Cabidoche (1966) and Delay (1975). For experiments on the terrain, fifteen colours have been used and 2,202 individuals were marked (Table 1).

\section{Captures and recaptures}

The cave studied consists of three levels with different features. That is why several stations have been chosen in each of them (Fig. 1): four in the upper network, eight in the middle one and three in the lower one. A marking colour was chosen for each of them. The first capture was carried out by putting out an organic bait (Shrimp head) for ten days. It has been demonstrated by Juberthie-Jupeau (1982) that the olfactory stimulus does not intervene in the concentration of Speonomus around the bait. It is exploratory behaviour of a chancy type which leads these animals to the bait. 

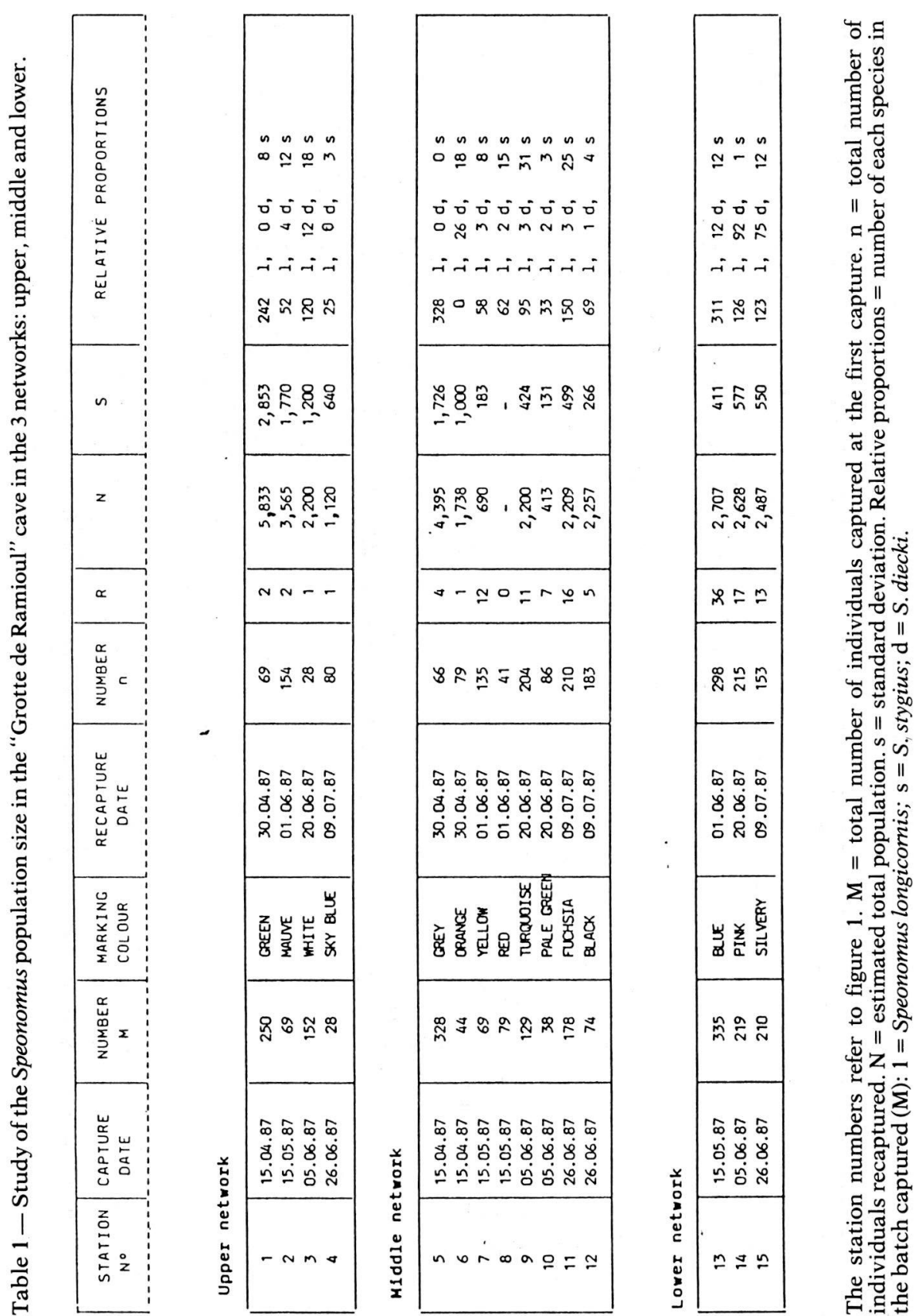


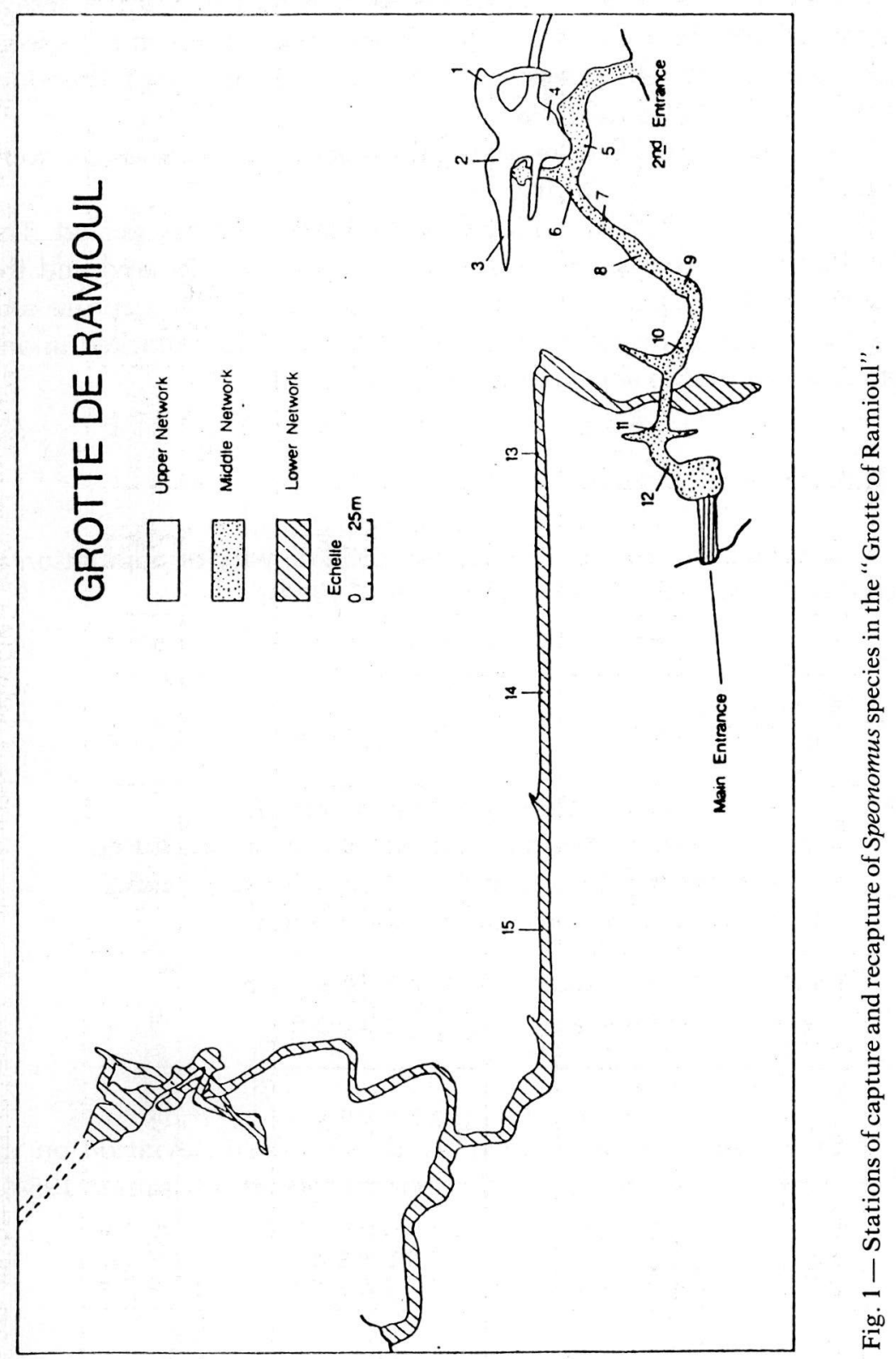


Only a gustative stimulus then keeps them near. The effectiveness of this behaviour through its principal components (movement speed, angulation and lenght of segment between each change of direction) has been studied (Tercafs, 1989).

After being marked in the laboratory, the individuals were released on the site of capture.

5 days later, bait was placed for a further 10-day period. The animals present at the end of the tenth day were captured and the proportion of marked individuals was calculated. The capture and recapture dates are shown in Table 1. No individual marked in one station was found in another one or in the S.S.M.

\section{Mathematical treatment}

The equation used for determining the density of population is that of Petersen, modified by Bayley (Roff, 1973):

$$
N=\frac{M(n+1)}{R+1}
$$

where $\mathrm{N}=$ estimate of the sizes of the population

$\mathbf{M}=$ number of animals marked when first captured

$\mathrm{n}=$ total number of animals counted on recaptures

$\mathrm{R}=$ number of marked animals retaken

The typical standard deviation of $\mathrm{N}$ is given by:

$$
S=\sqrt{\frac{M^{2}(n+1)(n-R)}{(R+1)^{2}(R+2)}}
$$

The equation used to calculate the standard deviation on the relative frequency ( $\mathrm{f} / \mathrm{n}$ ) of each Speonomus species is (Cramer, 1954):

$S=1.96 \times \frac{\sqrt{ } \mathrm{f}(\mathrm{n}-\mathrm{f})}{\mathrm{n}^{3}}$

where $\mathrm{f}=$ absolute frequency

$\mathrm{n}=$ sample size 


\section{RESULTS}

\section{Estimate of population densities in the cave}

The results are shown in Table 1. It appears that the effectiveness of the trapping varied from 28 to 250 individuals per station in the upper network, from 38 to 328 in the middle one and from 210 to 335 in the lower one. The number of marked individuals recaptured after fifteen days was still very low in the upper network (1 or 2 individuals), low in the middle network (between 0 and 16) and definitely higher in the lower network (13 to 36 individuals). These recaptures made it possible to estimate the populations in the different sampling stations but still with a very high standard deviation. In the upper network, the four stations studied gave a calculated value from $1,120 \pm 640$ to $5,833 \pm 2,853$. In the middle network ( 8 stations), the calculated values varied from $413 \pm 131$ to $4,395 \pm 1,726$. In the lower network ( 3 stations), they varied from $2,487 \pm 550$ to $2,707 \pm 411$.

The relative frequency of the three transplanted species were calculated on the basis of the first captures. Results are shown in Table 2 A. S. longicornis is dominant in the three networks, with a relative frequency of $0.89 \pm 0.03$ in the upper one, $0.85 \pm 0.02$ in the middle one and $0.73 \pm 0.03$ in the lower network. S. diecki had a relative frequency varying from $0.03 \pm 0.02$ in the upper network to $0.23 \pm 0.03$ in the lower one. The relative frequency of $S$. stygius varied from $0.03 \pm 0.01$ in the lower network to $0.11 \pm 0.02$ in the middle one.

Table 2A - Relative frequency of Speonomus species in the 3 networks. Mean value \pm standard deviation.

Network

Species

S. longicornis

S. diecki

S. stygius

$\begin{array}{llll}\text { Upper } & 0.89 \pm 0.03 & 0.03 \pm 0.02 & 0.08 \pm 0.02 \\ \text { Middle } & 0.85 \pm 0.23 & 0.04 \pm 0.01 & 0.11 \pm 0.02 \\ \text { Lower } & 0.73 \pm 0.31 & 0.23 \pm 0.03 & 0.03 \pm 0.01\end{array}$


Table 2B - Chi-square test for S. longicornis in the 3 levels

\begin{tabular}{lcc}
\hline Comparison between & Chi-square & Confidence limits \\
\hline & 3.98 & $0.05-0.01$ \\
Upper/middle & 42.3 & $>0.01$ \\
Upper/lower & 33.5 & $>0.01$ \\
Middle/lower & & \\
\hline
\end{tabular}

A chi-square test was used to compare the relative frequency of $S$. longicornis in the three levels (Table $2 \mathrm{~B}$ ). The results showed a high significant difference between the upper network and the lower network, and between the middle one and the lower one. A less significant difference appeared between the upper and the middle one.

The standard error was too high to test the two other species.

2. Extension of species in the superficial subterranean medium.

Twenty-eight trappings were made between April and June 1987. Nine stations gave positive results (51 individuals in all). They are all situated in the immediate proximity of the Ramioul cave and always in the limestone mass. No capture was made in the schist area.

\section{DISCUSSION}

Quite a lot of work has already been done to determine the number of individuals $(\mathrm{N})$ of cavernicolous populations. The method most used is the one based on the equation of Lincoln-Petersen (Cabidoche, 1966; Mitchell, 1970 a and 1970 b; Peck, 1975; Keith, 1975; Cooper, 1975; Delay, 1975; Mitchell et al., 1977; Sbordoni et al., 1983).

Published results as regards troglobiont coleopters can be summarized in Table 3 . The variations found basically stem from the size of the cave studied and the extent of the experiment. For 
Table 3 - Population size of troglobiont Coleopters in several caves in France.

\begin{tabular}{|c|c|c|c|}
\hline Name of cave & Situation & Species & Number References \\
\hline Pierre St Martin & Pyrénées (France) & $\begin{array}{l}\text { Aphaenops } \\
\text { loubensi }\end{array}$ & $\begin{array}{r}\text { 114-406 Cabidoche } \\
\text { (1966) }\end{array}$ \\
\hline Ste Catherine & Pyrénées (France) & $\begin{array}{l}\text { Speonomus } \\
\text { infernus }\end{array}$ & $\begin{array}{r}\text { 250-317 Juberthie } \\
(1960)\end{array}$ \\
\hline Pigailh & Ariège (France) & $\begin{array}{l}\text { Speonomus } \\
\text { longicornis }\end{array}$ & $\begin{array}{r}\text { 7,096-130,864 Delay } \\
\text { (1975) }\end{array}$ \\
\hline
\end{tabular}

instance, the results from the Ste Catherine and Pierre St Martin caves concern only one gallery, whereas those from the Pigailh cave concerned the whole of it. Results obtained at the Ramioul cave show the existence of large populations of Speonomus in the three networks, with estimates varying between 413 and 5,833 in the different sample stations but with a high standard deviation, given the small number of recaptures. The lower network of the cave, which was studied for only about a hundred metres is, however, fully colonized as far as the sinkhole (Hubart, in litt.) and a further study would need to be carried out to know the total population of that deep part of the network.

The number of individuals captured in a 10 day trapping were the following (mean \pm standard deviation see Table 1 for details):

Network

Upper

Middle

Lower
Capture

$$
\begin{aligned}
& 124.7 \pm 98.2 \\
& 117.3 \pm 96.7 \\
& 254.6 \pm 69.8
\end{aligned}
$$

\section{Recapture}

$$
\begin{gathered}
82.8 \pm 52.5 \\
125.5 \pm 66.6 \\
222.0 \pm 72.7
\end{gathered}
$$

Marked recaptured individuals are still small in number in the upper and middle levels, more numerous in the lower levels. Successive recaptures are respectively $1.5 \pm 0.6,7.0 \pm 5.6$ and $22.0 \pm$ 12.3. That higher value seems to indicate less scattering of the individuals in the lower level, after a release. The influence of a rather lower temperature in that level, responsible for less locomoto- 
ry activity, is not be excluded, but another factor may come into it: the geological structure of the galleries. In the lower level, the latter are but little fissured, whereas the middle and upper levels have fissured clayey areas, as well as heaps of speleothems and various deposits which increase the volume of available territory.

To estimate the whole population of the cave, we must considered two hypotheses:

a) all the Speonomus of the cave network belong to a single population. In this case the population size of the cave network could be calculated by an application of the Lincoln-Petersen formula, assuming as true parameters $\mathrm{R}, \mathrm{M}$ and $\mathrm{n}$, the sums of these parameters observed in the sampling stations belonging to the studies cave network.

b) the Speonomus are divided in several populations, without exchanges during the sampling time. In this case, the population size of the cave networks is the sum of $\mathrm{N}$ calculated from each sampling station by the Lincoln-Petersen formula. Because the marked animals were found exclusively in the sampling station where they were marked, it seems that this second hypothesis is more likely. So the population of the cave network could be estimated in this way. For the upper network (sampling station \#1 to \#4), the total is 12,718 . For the middle network (station \#5 to \#12), the total is 7,822 . In this level, where access is difficult, the number of stations (3), limited to a hundred or so metres in an accessible level of some $700 \mathrm{~m}$, leads to an under-estimate. It is therefore logical to extrapolate using the calculated estimate density of one sampling station $(2,607 \pm 111)$, multiplying by 7 (ratio between the whole lower level, $700 \mathrm{~m}$, and the studied section, $100 \mathrm{~m}$ ) i.e. 18,249 individuals. The total population of the cave would therefore be 44,869 individuals in the accessible levels. There is manifestely scattering in the S.S.M., as sample surveys show presence in the vicinity of the cave ( 9 positive results in a $50 \mathrm{~m}$ area, negative results beyond that). An accurate estimate of the population is impossible here. Bearing in mind that captures take place only during exploratory behaviour, it is necessary for thousands of individuals to be present in the S.S.M. for the results obtained to be accounted for.

The behaviour of the Speonomus when seeking food is based on a "Brownian" type of search policy. This fact is an advantage when using the capture-recapture method, as this presupposes that 
marked individuals quickly mix with the existing population.

Analysis of the relative frequency of the Speonomus species shows that Speonomus longicornis is largely predominant (between 0.73 to 0.89 , depending on the network). This situation is similar to that observed in the stations of origin; perhaps the species has a higher reproduction rate. Also, during the transplantation, 200 individuals were released, as against 80 Speonomus diecki and 100 Speonomus stygius. The proportions of Speonomus diecki and Speonomus stygius vary with the networks. Speonomus diecki seems dominant in the lower network, whilst Speonomus stygius seems dominant in the middle and upper networks. These variations are perhaps to be set in relation with the diversity of trophic resources in the three networks.

Recent capture has been made in the schist area in an artificial gallery at a distance of 120 metres from the cave entrance (Hubart, 1990). Its chemical composition (ampelitic schist calcined not so long for the extraction of alun), is not an obstacle to the expansion of the Speonomus species.

\section{CONCLUSIONS}

It is important to recall, first of all, the context in which the faunal transplantation took place in 1969 and 1970. The authors (Bouillon and Hubart, 1982) wanted to show that the superficial subterranean medium (S.S.M.) was the major habitat of cavernicoles, caves accessible to man being but a special case. By placing troglobionts in a new-medium - the Ramioul cave -, they desidered to carry out a controlled experiment in the study of expansion of a group of troglobiont species to the S.S.M. The Ramioul cave was chosen because it comprised no species that could compete with the transplanted Speonomus (Delhez et al., 1973). Furthermore, it is situated in an area where surface expansion is limited.

This transplantation experiment had already been carried out unintentionally at the Moulis cave (Ariège, France). That cave houses the underground laboratory of the French National Centre of Scientific Research, and numerous specimens belonging to various troglobionts escaped from the breeding places. They were found in the surrounding environment, but as neither the number of indivi- 
duals that escaped nor their date of departure was known, it was impossible to draw conclusions (Christiansen, 1970). In the case of the Ramioul cave, the experimental conditions were controlled from the start and the following conclusions can be drawn:

- after 18 years the three species of Speonomus, Speonomus longicornis, Speonomus diecki and Speonomus stygius have developed large populations in the three networks of the cave;

- Speonomus longicomis considerably dominates the other two species;

- the nearby superficial subterranean medium (S.S.M.) is also colonized by the three species including the schist area.

\section{ACKNOWLEDGMENTS}

The authors thank J. M. Hubart, Head of the Ramioul Underground Biology Laboratory, for his assistance throughout this study, R. Moors for the statistic treatment and an anomymous referee for his valuable cristicism.

\section{REFERENCES}

BAYLEY, N.T.J. 1951. On estimating the size of mobile populations from capturerecapture data. Biometrica 38: 293-396.

BOUILLON, M. et J.M. HUBART 1982. Premiers résultats d'une expérience de transplantation de cavernicoles pyrénéens dans une grotte belge. Bull. Soc. Roy. Belg. Et. Géol. Archéol. Cherch. Wallonie 16: 291-327.

CABIDOCHE, M. 1966. Contribution à la connaissance des Trechinae cavernicoles pyrénéens. Thèse Université, Paris, 280 pp.

COOPER, J.C. 1975. Ecological and behavioral studies in Shelta Cave, Alabama, with empahasis on decapod crustaceans. Ph. D. dissertation, University of Kentucky, $255 \mathrm{pp}$.

CRAMER, H. 1954. The elements of probability theory and some of its applications. John Wiley and Sons eds, New York, 282 pp.

CHRISTIANSEN, K. 1970. Invertebrate populations in the Moulis Cave. Ann. Spéléol. 25: 243-273.

DELAY, B. 1975. Etude quantitative de populations monospécifiques de coléoptères hypogés par la méthode des marquages et recaptures. Ann. Spéléol. 30: 195-206.

DELHEZ, F. R. GILSON, J.M. HUBART, 1973. Etude préliminaire de la faune de la grotte de Ramioul. Bull. Soc. Roy. Belg. Et. Géol. Archéol. Cherch. Wallonie 22: 329-349.

HUBART, J.M. 1983. Note sur le milieu souterrain superficiel de Ramioul. Bull. Soc. recherches biosp. 1: 14-21.

HUBART, J.M. 1990. Introduction de Coléoptères troglobies pyrénéens dans la grotte de Ramioul (Flémalle, Belgique). Nouvelles données et bilan actuel. Bull. Soc. Roy. Belg. Et. Géol. Archéol. Cherch. Wallonie 30: 103-113.

JUBERTHIE, C. 1969. Etude écologique des larves de Speonomus infernus dans la grotte de Sainte-Catherine. Ann. Spéléol. 24: 563-577. 
JUBERTHIE-JUPEAU, L. 1983. Etude expérimentale de la présence de Colséoptères Bathysciinae souterrains autour de substances alimentaires. Mém. biosp. 37: 369-376.

KEITH, J.H. 1975. Seasonal changes in a population of Pseudophtalmus tenuis (Coleoptera, Carabidae) in Murray Spring Cave, Indiana. A preliminary report. Int. J. Speleol. 7: 33-44.

MITCHELL, R.W. 1970 a. Population size and dispersions and species associations of a mexican cavernicole ricinuleid. Ciencia 27: 63-74.

MITCHELL, R.W. 1970 b. Total number and density estimates of some species inhabiting Fern Cave, Texas. Ann. Spéléol. 25: 73-90.

PECK, S.B. 1975. A population study of the cave beetle Ptomaphagus loedingi (Coleoptera: Leiodidae, Catopinae). Int. J. Speleol. 7: 19-32.

QUINIF, Y. 1985. Aspects morphosédimentaires de la grotte de Ramioul. Bull. Soc. Roy. Belg. Et. Géol. Archéol. Cherch. Wallonie 25: 170-178.

ROFF, D.A. 1973. On the accuracy of some mark-recapture estimators. Oecologia 12: 15-34.

SBORDONI, V., G. CARCHINI et M. RAMPINI. 1983. Un test della efficienza del metodo di marcaggio e ricattura nella stima di popolazioni di ortotteri cavernicoli. Atti XIII Congr. Naz. It. Ent. Sestriere - Torino, 1983: 291-294.

TERCAFS, R. 1989. Simulation de stratégie de recherches optimales pour des espèces troglobies. Mém. biosp., 16: 189-195. 